\title{
Subpreputial carriage of aerobic micro-organisms and balanitis
}

\author{
R K BHARGAVA AND R N T THIN \\ From the Department of Genital Medicine, St Bartholomew's Hospital, London
}

SUMMARY Men attending a genitourinary medicine clinic had an appreciably higher prevalence of subpreputial infection with group B streptococci (GBS) than with Staphylococcus aureus or coliform bacilli. Carriage of GBS was similar in older and younger age groups and was higher in homosexuals than heterosexuals and in those with balanitis than those without. Thus, while GBS may cause balanitis in heterosexuals, sexual transmission is unimportant; in contrast sexual transmission of GBS may be more common among homosexuals but balanitis is rare.

\section{Introduction}

Serious group B streptococcal infection among infants increased in incidence in the 1950s and 1960s, though it was more of a problem in North America and the rest of Europe than in Britain. ${ }^{1}$ Babies with the early onset form of the infection acquire the micro-organism from their mothers, and in the USA Knox ${ }^{2}$ noted that 32 of 112 parturient women in the lower socioeconomic groups harboured group B streptococci (GBS) in the vagina. Concern has recently been expressed in Britain about streptococcal disease in the newborn, and sexual transmission between parents has been postulated; ${ }^{3}$ this may explain the difficulty in eradicating the organism during pregnancy. An association has also been suggested between balanitis and carriage of GBS (unpublished data). ${ }^{4}$

In this study we examined the carriage rate of GBS in men with gonorrhoea, non-specific urethritis, candidosis, and other sexually transmitted diseases (STDs) or no STD, and related it to age, country of birth, and sexual orientation. We noted the presence or absence of balanitis and for comparison we also performed cultures for Staphylococcus aureus and coliform bacilli.

\section{Patients and methods}

Uncircumcised men who had not received antibiotics in the previous month and attended the department of genital medicine, St Bartholomew's Hospital,

Address for reprints: Dr R N T Thin, Department of Genitourinary Medicine, St Thomas's Hospital, London SE1

Accepted for publication 22 September 1982
London, with a fresh problem between 1 July and 31 December, 1981, were studied. The diagnosis of balanitis was based on the presence of pronounced generalised or patchy redness with or without superficial erosions on the glans or under the prepuce or abnormal exudate but excluding smegma. The diagnosis of other STDs has been described elsewhere; ${ }^{5}$ early syphilis in particular was excluded when erosions were present by darkfield microscopy on at least three occasions.

In addition to these diagnostic investigations a swab was taken from the subpreputial space, a Gramstained smear prepared, and a Sabouraud slope inoculated; the swab was then placed in Amies medium for transport to the microbiology laboratory. Swabs were kept at room temperature and within 18 hours were inoculated on to horse blood agar, Islam's agar, ${ }^{7}$ and MacConkey agar, to isolate Staphylococcus species, Streptococcus species, Enterobacteriaceae, Pseudomonas species, and Candida species. Only men with positive culture results were included.

For simplicity the different types of group B haemolytic streptococci (GBS) have been grouped together. For the purpose of this study the term homosexual included bisexual. Statistical comparisons were made using the $\chi^{2}$ test.

\section{Results}

A total of 203 patients were included in the study; $40 \%$ were in the 21-30 year age group and 30\% in the 31-40 year group. More men were aged 35 years and under than 36 years and over, but the carriage rates were similar in the two groups $(19.5 \%$ and $20 \%$ respectively). One hundred and seventy four men were born 
TABLE I Balanitis in disease groups related to country of birth

\begin{tabular}{|c|c|c|c|c|c|c|}
\hline Country of birth & Gonorrhoea & $N S U$ & Candidosis & Other STD & No other STD & Total \\
\hline $\begin{array}{l}\text { United Kingdom } \\
\text { No of patients } \\
\text { No with balanitis }\end{array}$ & $\begin{array}{r}28 \\
8\end{array}$ & $\begin{array}{r}26 \\
1\end{array}$ & $\begin{array}{l}26 \\
20\end{array}$ & $\begin{array}{r}10 \\
0\end{array}$ & $\begin{array}{r}84 \\
6\end{array}$ & $\begin{array}{r}174 \\
35\end{array}$ \\
\hline $\begin{array}{l}\text { Elsewhere } \\
\text { No of patients } \\
\text { No with balanitis }\end{array}$ & $\begin{array}{l}4 \\
0\end{array}$ & $\begin{array}{l}4 \\
1\end{array}$ & $\begin{array}{l}5 \\
4\end{array}$ & $\begin{array}{l}2 \\
0\end{array}$ & $\begin{array}{r}14 \\
0\end{array}$ & $\begin{array}{r}29 \\
5\end{array}$ \\
\hline
\end{tabular}

TABLE II Association of micro-organisms with balanitis

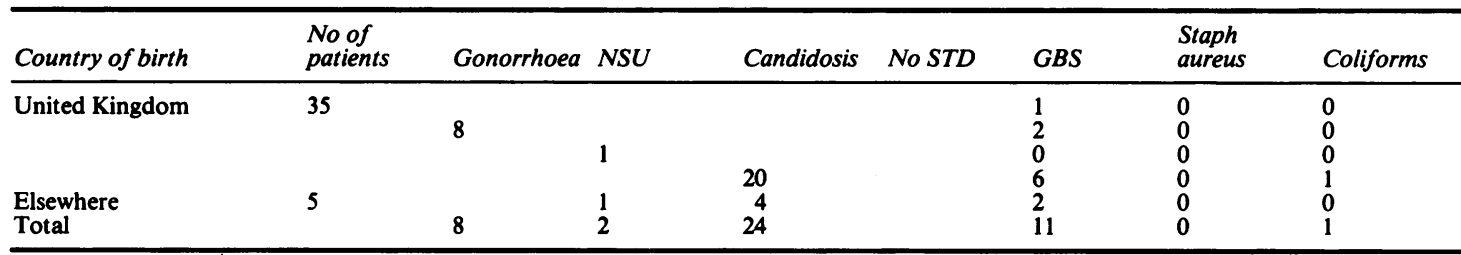

NSU = non-specific urethritis; GBS = group B streptococci

TABLE III Carriage of micro-organisms in men without balanitis

\begin{tabular}{lllllll}
\hline Country of birth & Gonorrhoea & NSU & Candidosis & Other STD & No STD & Total No of cases \\
\hline United Kingdom (n=139) & 1 & & & & & \\
GBS & 2 & 4 & 3 & 5 & 7 & 22 \\
Staphylococci & 0 & 2 & 0 & 1 & 2 & 7 \\
Coliforms & 1 & 0 & 2 & 0 & 1 & 3 \\
Elsewhere (n=25) & 1 & 0 & 0 & 0 & 4 & 7 \\
GBS & 0 & 0 & 0 & 0 & 0 & 0 \\
Staphylococci & Coliforms & & & & & 0 \\
\hline
\end{tabular}

GBS = group B streptococci

in Britain, eight in Asia, six in the West Indies, five in South Africa, and 10 elsewhere. The prevalence of balanitis and its association with other diseases is shown in table I; $24(77 \cdot 4 \%)$ of 31 patients with candidosis and eight of 32 men with gonorrhoea had balanitis, but only two $(6 \cdot 7 \%)$ of 30 patients with nonspecific urethritis and six of 98 men without disease had balanitis. Thirty-five $(20 \cdot 1 \%)$ of the 174 men born in Britain and five $(17 \cdot 2 \%)$ of the 29 born elsewhere had balanitis.

The carriage of micro-organisms in different diseases is shown in table II; GBS was harboured more frequently than the other two. It was also more strongly associated with balanitis than were the other organisms. Carriage of GBS in those men without balanitis born in Britain was less common than among those born elsewhere: $22(15 \cdot 8 \%)$ of 139 compared with seven $(28 \%)$ of $25\left(\chi_{1}^{2}=2 \cdot 16, p>0 \cdot 05\right)$ (table III). Carriage of GBS among those men with and without balanitis born in Britain was found in $31(17 \cdot 8 \%)$ of 174 cases and in those born elsewhere it was 15 of 30 , while in those born in West Africa and the West Indies it was found in three of nine and in three of five born in Asia.

No case of balanitis has found among the homosexuals, but they had higher rates of carriage of all three micro-organisms than did heterosexuals (table IV). Carriage of GBS among homosexuals $(39.3 \%, 11$ of 28 cases) was higher than among heterosexuals $(16 \cdot 6 \%, 29$ of 175 cases $)\left(\chi_{1}^{2}=7 \cdot 92\right.$, $\mathrm{p}<0.01)$.

TABLE IV Isolation of micro-organisms in relation to sexual behaviour

\begin{tabular}{lllll}
\hline & \multicolumn{4}{c}{ Micro-organisms isolated: } \\
\cline { 4 - 5 } Disease & $\begin{array}{l}\text { No of } \\
\text { patients }\end{array}$ & GBS & $\begin{array}{l}\text { Staph } \\
\text { aureus }\end{array}$ & Coliforms \\
\hline Homosexuals & & & & \\
$\quad$ No other STD & 8 & 3 & 1 & 0 \\
Gonorrhoea & 7 & 3 & 2 & 1 \\
NSU & 5 & 2 & 1 & 0 \\
Candidosis & 4 & 2 & 0 & 0 \\
$\quad$ Others & 4 & 1 & 0 & 0 \\
Total & 28 & 11 & 4 & 1 \\
Heterosexuals & & & & \\
$\quad$ No other STD & 86 & 9 & 1 & 0 \\
Gonorrhoea & 25 & 1 & 1 & 0 \\
NSU & 25 & 4 & 3 & 0 \\
Candidosis & 27 & 11 & 0 & 2 \\
$\quad$ Others & 12 & 4 & 1 & 0 \\
Total & 175 & 29 & 6 & 2 \\
\hline
\end{tabular}

GBS = group B streptococci; NSU = non-specific urethritis 


\section{Discussion}

Previous studies of GBS in the genital tract have concentrated on women ${ }^{8}$ and on urethral carriage in men. ${ }^{3}$ In our study the carriage of GBS was similar in the younger and presumably more sexually active age groups than in the older groups, which contradicts the theory that this micro-organism may be sexually transmitted as suggested by Weindling et $a^{3}$ who studied heterosexuals. The orientation of men studied by Wallin and Forsgren ${ }^{9}$ was not clear but these workers concluded that meatal carriage could not be related to promiscuity. As expected candidosis and to a lesser extent gonorrhoea were associated with balanitis. GBS was more strongly associated with balanitis than staphylococci or coliform bacilli, but among homosexuals, none of whom had balanitis, carriage was higher $(39 \cdot 3 \%)$ than among heterosexuals $(16 \cdot 6 \%)$. This casts doubt on an important causative role for GBS in balanitis.

The higher overall carriage of GBS among the nonUK born, especially perhaps Asians, West Indians, and West Africans, compared with those born in Britain is interesting, but because of the small numbers conclusions cannot be drawn.

The high carriage of GBS among homosexuals suggests that this micro-organism is sexually transmitted among them, perhaps by orogenital contact. Homosexuals also practise oroanal contact and this might be a factor in coliform carriage but the results indicate that the subpreputial space is not an important site for coliform or staphylococcal carriage.

Thus the findings in this study suggest that homosexuals carry GBS but rarely get balanitis. Although GBS may cause balanitis in heterosexuals sexual transmission does not appear to be an important factor.

\section{References}

1. Anonymous. Neonatal infection with group B streptococci (Editorial). Lancet 1981;ii:181-2.

2. Knox JM. Group B streptococcal infection. Br J Vener Dis 1979;55:118-20.

3. Weindling AM, Hawkins JM, Coombes AM, Stringer J. Colonisation of babies and their families by group B streptococci. BrMed J 1981;283:1503-5.

4. Brook I. Group B $\beta$-haemolytic streptococci causing balanitis South Med J 1980;73:1095-7.

5. Thin RN, Leighton M, Dixon MJ. How often is genital yeast infection sexually transmitted. $B r$ Med J 1977; ii:93-4.

6. Simmons PD. Podophyllin $10 \%$ and $25 \%$ in the treatment of anogenital warts Br J Verier Dis 1981;57:208-9.

7. Islam AKMS. Rapid recognition of group B streptococci. Lancet 1977;i:256-7.

8. Finch RG, French GL, Phillips I. Group B streptococci in the female genital tract. Br Med J 1976;i:1245-7.

9. Wallin J, Forsgren A. Group B streptococci in venereal disease clinic patients. Br J Vener Dis 1975;51:401-4. 